\title{
Synthesis and evaluation of the thermal behavior of flavonoids
}

\author{
Thermal decomposition of flavanone and 6-hydroxyflavanone
}

\author{
Leonardo Miziara Barboza Ferreira ${ }^{1}$ Marcelo Kobelnik ${ }^{2} \cdot$ Luis Octavio Regasini $^{3}$. \\ Luiz Antonio Dutra ${ }^{3} \cdot$ Vanderlan da Silva Bolzani $^{3} \cdot$ Clóvis Augusto Ribeiro $^{1}$
}

Received: 18 September 2015/Accepted: 5 October 2016/Published online: 17 October 2016

(C) Akadémiai Kiadó, Budapest, Hungary 2016

\begin{abstract}
Flavonoids in the broad sense of the term are virtually universal plant pigments. Synthesis of flavanone and 6-hydroxyflavanone was carried out and identified by $\mathrm{H}$ and C NMR. Details concerning the thermal behavior were evaluated by thermogravimetry under oxygen and nitrogen purge gases. Additionally, the kinetic studies were evaluated from several heating rates $\left(5,10\right.$ and $\left.20^{\circ} \mathrm{C} \mathrm{min}^{-1}\right)$ and sample mass of $2 \mathrm{mg}$ in open crucibles. The obtained data were evaluated with the isoconversional method, where the values of activation energy $\left(E_{\mathrm{a}} / \mathrm{kJ} \mathrm{mol}^{-1}\right)$ were plotted in function of the conversion degree $(\alpha)$. The results of thermal behavior of the flavanone under a nitrogen purge gas showed that this compound has a homogeneous degradation process while the hydroxyl group in the aromatic ring of 6-hydroxyflavanone there are two mass losses.
\end{abstract}

Keywords Flavanones · NMR spectra Thermogravimetry

\section{Introduction}

Flavonoids in the broad sense of the term are virtually universal plant pigments [1]. They are responsible for the color of flowers, fruits and leaves. Their structures

Marcelo Kobelnik

mkobelnik@gmail.com

1 Departamento de Química Analítica, Instituto de Química, UNESP_Universidade Estadual Paulista,

C.P. 355, Araraquara, SP 14800-900, Brazil

2 Centro Universitário do Norte Paulista, UNORP, São José do Rio Preto, SP, Brazil

3 Departamento de Química Orgânica, Instituto de Química, UNESP_-Universidade Estadual Paulista, C.P. 355, Araraquara, SP 14800-900, Brazil absorb near-UV radiation, due to extensive chromophores, and are visible to many arthropod and bird pollinators [2]. Flavanones (or 2-phenylchroman-4-ones) are flavonoids containing one sigma bond between carbons C-2 and C-3 (ring C) carbons. They are responsible for several organoleptic properties of food, including the taste. Interestingly, naringin-7-rutinoside, a glycosylated compound obtained from the peel of the grapefruit (Citrus paradisi), is very bitter and astringent [3]. Nowadays, the study of natural and synthetic flavanone derivatives has significantly increased because these compounds exhibited potent chemopreventive and pharmacological activities such as: antioxidant, antiinflammatory, anticancer, anti-diabetic and antimicrobial [4-8].

Although the antioxidant activity of the 6-hydroxyflavanone is not as good as flavonoids with multiple hydroxyl substituents [9], this compound shows other good medicinal properties such as vaso-relaxing effects [10] and an anticancer effect through extrinsic and intrinsic apoptotic pathways [11].

In this work, we report on the synthesis and thermal characterization of flavanone and 6-hydroxyflavanone. The results obtained with the present study improve the knowledge on these flavonoids. The experiments were carried out with one only mass sample in nitrogen and oxygen purge gases, in order to determine the effect of this change on obtained results as well as on the kinetic behavior. Moreover, the isoconversional method is used as a way of obtaining reliable and consistent kinetic information and also because it avoids the use of explicit kinetic models [12-16]. Thus, the activation energy $\left(E_{\mathrm{a}} / \mathrm{kJ} \mathrm{mol}^{-1}\right)$ data were obtained applying the method proposed by Capela et al. [16]. 


\section{Experimental}

\section{General procedures for synthesis of flavanones}

Flavanone (1) and 6-hydroxyflavanone (2) were synthesized as previously described by Zeraik et al. [17], with minor modifications. In a $30-\mathrm{mL}$ vial, the appropriated acetophenone $(2.5 \mathrm{mmol})$ and lithium hydroxide monohydrate $(0.5 \mathrm{mmol})$ were dissolved in methanol $(10 \mathrm{~mL})$, and the mixture was stirred at $5{ }^{\circ} \mathrm{C}$ for $10 \mathrm{~min}$ followed by the addition of benzaldehyde $(2.70 \mathrm{mmol})$. The reaction mixture was stirred at room temperature and monitored by TLC using hexanes/ethyl acetate (9:1) as the mobile phase. The reaction was quenched after 6 days by pouring into $100 \mathrm{~mL}$ of stirring ice cold water, and a stick mass was observed in the aqueous solution after quenching. Thus, the product was extracted by ethyl acetate $(3 \times 100 \mathrm{~mL})$, dried over sodium sulfate and concentrated under reduced pressure. The crude products were purified by flash chromatography using hexanes/ethyl acetate as the solvent system in increasing the order of polarity. $( \pm$ )-Flavanone (1) and its hydroxylated derivative (2) were identified by ${ }^{1} \mathrm{H}$ and ${ }^{13} \mathrm{C}$ NMR spectra data obtained from a Varian DRX-500 spectrometer $(11.7 \mathrm{~T})$. Chemical shifts $(\delta)$ were expressed in ppm. Coupling constants $(J)$ were expressed in $\mathrm{Hz}$, and splitting patterns are described as follows: $\mathrm{s}=$ singlet; $\mathrm{d}=$ doublet $; \mathrm{m}=$ multiplet; $\mathrm{dd}=$ doublet of doublets (Fig. 1).

$( \pm)$-Flavanone (1). ( \pm )-2-phenylchroman-4-one. It was obtained as a pale yellow solid in $88 \% .{ }^{1} \mathrm{H} \mathrm{NMR}(500 \mathrm{MHz}$, DMSO- $\left.d_{6}\right) \delta=7.85$ (dd; $\left.J=8.0,1.5 \mathrm{~Hz}, \mathrm{H}-5\right), 7.40$ (m; H-6-H-8 and H-3'-H-5'), 6.96 (dd; $J=7.0,1.5 \mathrm{~Hz}, \mathrm{H}-2^{\prime}$ and $\left.\mathrm{H}-6^{\prime}\right), 5.40(\mathrm{dd} ; J=13.0,3.0 \mathrm{~Hz}, \mathrm{H}-2), 3.00(\mathrm{dd}$; $J=17.0,13.0 \mathrm{~Hz}, \mathrm{H}-3 \mathrm{~b}$ ), 2.81 (dd; $J=17.0,3.0 \mathrm{~Hz}$, H-3a). ${ }^{13} \mathrm{C}$ NMR (125 MHz, DMSO- $\left.d_{6}\right) \delta=191.9$ (C-4), 161.5 (C-9), $138.7\left(\mathrm{C}-1^{\prime}\right), 136.1(\mathrm{C}-7), 128.8\left(\mathrm{C}-3^{\prime}\right.$ and C-5'), $128.7\left(\mathrm{C}-4^{\prime}\right), 127.0\left(\mathrm{C}-2^{\prime}\right.$ and C-6'), 126.1 (C-5), 121.6 (C-10), 120.9 (C-6), 118.1 (C-8), 79.5 (C-2), 44.6 (C-3).

$( \pm)$-6-Hydroxyflavanone (2). ( \pm )-6-hydroxy-2-phenyl chroman-4-one. It was obtained as an intense yellow solid in $84 \%$. ${ }^{1} \mathrm{H}$ NMR $\left(500 \mathrm{MHz}\right.$, DMSO- $\left.d_{6}\right) \delta=9.40(\mathrm{~s}$; $6-\mathrm{OH}), 7.52\left(\mathrm{dd} ; J=8.5,1.5 \mathrm{~Hz}, \mathrm{H}-2^{\prime}\right.$ and $\left.\mathrm{H}-6^{\prime}\right), 7.40(\mathrm{~m}$; H-3'-H-5'), 7.12 (d; $J=3.0 \mathrm{~Hz}, \mathrm{H}-5), 7.04$ (dd; $J=9.0$, $3.0 \mathrm{~Hz}, \mathrm{H}-7), 6.95$ (d; $J=9.0, \mathrm{H}-8), 5.54$ (dd; $J=13.0$,
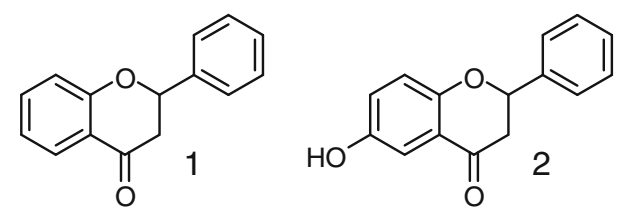

Fig. 1 Structures of ( \pm )-flavanone (1) and ( \pm )-6-hydroxyflavanone (2)
$3.0 \mathrm{~Hz}, \mathrm{H}-2), 3.16$ (dd; $J=17.0,13.0 \mathrm{~Hz}, \mathrm{H}-3 \mathrm{~b}), 2.78$ (dd; $J=17.0,3.0 \mathrm{~Hz}, \mathrm{H}-3 \mathrm{a}) .{ }^{13} \mathrm{C}$ NMR $\left(125 \mathrm{MHz}\right.$, DMSO- $\left.d_{6}\right)$ $\delta=191.6(\mathrm{C}-4), 154.3(\mathrm{C}-6), 151.5(\mathrm{C}-9), 139.1\left(\mathrm{C}-1^{\prime}\right)$, $128.4\left(\mathrm{C}-3^{\prime}\right.$ and $\left.\mathrm{C}-5^{\prime}\right), 128.3\left(\mathrm{C}-4^{\prime}\right), 126.4\left(\mathrm{C}-2^{\prime}\right.$ and $\left.\mathrm{C}-6^{\prime}\right)$, 124.5 (C-10), 120.8 (C-7), 118.9 (C-8), 109.9 (C-5), 78.7 (C-2), 43.6 (C-3).

\section{Thermal behavior}

TG/DTG curves were obtained from a SDT 2960, from TA Instruments, respectively. The TG/DTG curves were obtained using a sample of about $2 \mathrm{mg}$ in an $\alpha$-alumina crucible with heating rates of 5,10 and $20{ }^{\circ} \mathrm{C} \mathrm{min}{ }^{-1}$ under nitrogen and oxygen purge gases with flow of $100 \mathrm{~mL} \mathrm{~min}^{-1}$.

\section{Kinetic methodology}

The method described below to use as kinetic methodology was widely exposed in other work carried out [12-15]. In this work, the kinetic parameters are obtained using an isoconversional method on approximation to the temperature integral based on the convergent of a Jacobi fraction, proposed by Capela et al. [16]. Thus, it should be noted that this is not a self-plagiarism but is aimed at the use of a standard methodology. Therefore, the use of methodology standard analysis allows to reproduce the results obtained by other research groups without the need to complicate the understanding of extraction procedures and analysis. In addition, to use this kinetic methodology, we use the "least square method" and Origin software.

Capela and Ribeiro et al. approached that it is given by the following equation:

$$
\int_{x}^{\infty} \frac{\exp (-z)}{z^{2}} \mathrm{~d} z=\frac{\exp (-x)}{x} \frac{x^{3}+14 x^{2}+46 x+24}{x^{4}+16 x^{3}+72 x^{2}+96 x+24}
$$

A characteristic experimental curve presents the conversional fraction, $\alpha$, as a function of the temperature for a given heating rate, $\beta$. For each fixed value of $\alpha$, there are corresponding values $T_{\alpha}$ for temperature, values $E_{\alpha}$ for activation energy and values $A_{\alpha}$ for the pre-exponential factor.

Usually, the kinetic parameters are made under nonisothermal conditions, defined by

$\beta=\frac{A E}{R g(\alpha)} \int_{E / R T}^{\infty} \frac{\exp (-z)}{z^{2}} \mathrm{~d} z$

where $\beta=\mathrm{d} T / \mathrm{d} t$ is a constant heating rate ( $T$ is the temperature and $t$ is the time), $g(\alpha)$ is the integral form of the 
reaction model as function of the extent of reaction $\alpha, A$ is the pre-exponential factor, $E$ is the activation energy and $R$ is the gas constant.

The evaluation of the integral on the right side of Eq. (2), known as temperature integral, is required, but this integral does not have an exact analytical solution. Thus, it is convenient to approximate the integral of temperature for some function that yields suitable estimates to these kinetic parameters.

Replacing the integral in Eq. (2) by the approximation given in Eq. (1) is obtained the following expression for heating rate $\beta$ as function of the $x_{\alpha}=10^{3} / R T_{\alpha}$ :

$\beta=\frac{\exp \left(B_{\alpha}-E_{\alpha} z_{\alpha}\right)}{x_{\alpha}} \frac{E_{\alpha}^{3} z_{\alpha}^{3}+14 E_{\alpha}^{2} z_{\alpha}^{2}+46 E_{\alpha} z_{\alpha}+24}{E_{\alpha}^{4} z_{\alpha}^{4}+16 E_{\alpha}^{3} z_{\alpha}^{3}+72 E_{\alpha}^{2} z_{\alpha}^{2}+96 E_{\alpha} z_{\alpha}+24}$

where the activation energy is in $\mathrm{kJ} \mathrm{mol}^{-1}$ and the parameter $B_{\alpha}$ is defined as:

$B_{\alpha}=\ln \left(\frac{10^{3} A_{\alpha}}{R g(\alpha)}\right)$

The estimates of the $E_{\alpha}$ and $B_{\alpha}$ can be obtained by the nonlinear fitting of Eq. (3) to the $\beta$ values as function of $x_{\alpha}$.

Once the $g(\alpha)$ function has been determined for each conversional fraction $\alpha$, the estimation of the Arrhenius pre-exponential factor can be obtained from Eq. (4) and is given by the following equation:

$\hat{A}_{\alpha}=\frac{R}{10^{3}} \exp \left(\hat{B}_{\alpha}\right) g(\alpha)$

\section{Results and discussion}

TG/DTG curves of the flavanone and 6-hydroxyflavanone are reported in Figs. 2 and 3 in oxygen and nitrogen purge gases.

The analysis of the flavanone under an oxygen purge gas shows only one mass loss of $98.01 \%$ between 150 and $276{ }^{\circ} \mathrm{C}$, which was attributed to thermal decomposition. From the analysis of 6-hydroxyflavanone under oxygen, we can see that this compound exhibited a mass loss of $40.03 \%$ between 180 and $314{ }^{\circ} \mathrm{C}$, which was also attributed to thermal decomposition. Moreover, this compound shows one further stage of thermal decomposition, with a mass loss of $53.66 \%$, which occurred in overlapping reactions up to $590{ }^{\circ} \mathrm{C}$. Furthermore, the 6-hydroxyflavanone showed a higher thermal stability that the flavanone, which is due to the presence of the hydroxy group in the aromatic ring.

The thermal decomposition of flavanone under a nitrogen purge gas (Fig. 3) occurs in only one stage from 150 to

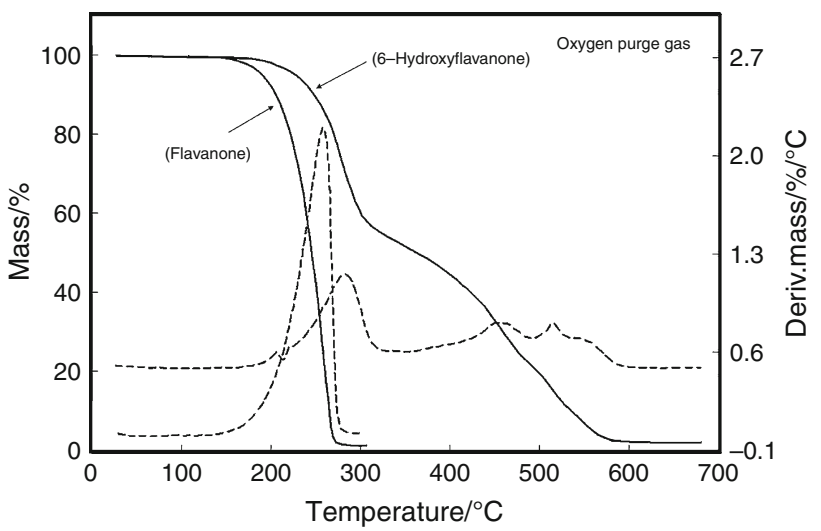

Fig. 2 TG/DTG curves of flavanone and 6-hydroxyflavanone with mass sample of $2 \mathrm{mg}$ in an oxygen purge gas and heating rate of $20{ }^{\circ} \mathrm{C} \min ^{-1}$

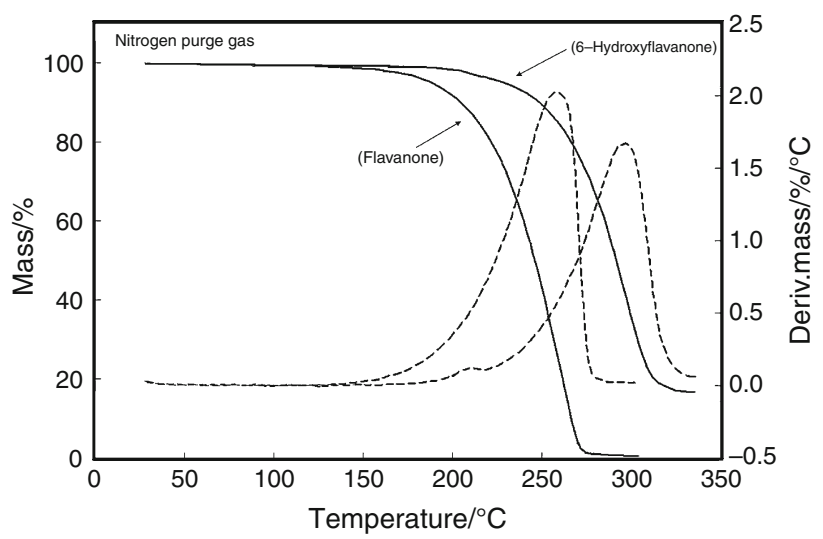

Fig. 3 TG/DTG curves of flavanone and 6-hydroxyflavanone with mass sample of $2 \mathrm{mg}$ in a nitrogen purge gas, heating rate of $20{ }^{\circ} \mathrm{C} \min ^{-1}$, in alumina crucible

$535{ }^{\circ} \mathrm{C}$, with a mass loss of $97.34 \%$ and with formation of a low quantity carbonaceous residue. For the thermal decomposition of 6-hydroxyflavanone, there are two mass losses between $190-217$ and $217-328{ }^{\circ} \mathrm{C}$ with a loss of 2.02 and $85.34 \%$, respectively.

In addition, Fig. $4 \mathrm{a}, \mathrm{b}$ shows the DSC analysis carried out under oxygen purge gas with heating rate of $20{ }^{\circ} \mathrm{C} \min ^{-1}\left(V_{\mathrm{h}}\right)$. The melting point $\left(T_{\mathrm{mp}}\right)$ of these compounds can seen in the first endothermic peak, which are ascribed in $78.5^{\circ} \mathrm{C}$ to flavanone and $215^{\circ} \mathrm{C}$ to 6-hydroxyflavanone (both are better seen in Figure B). The DSC curves of flavanone show an event between 210 and $265{ }^{\circ} \mathrm{C}$, which is in agreement with mass loss observed in the TG curve, while the 6-hydroxyflavanone does not show event during thermal decomposition in interval of 250 and $450{ }^{\circ} \mathrm{C}$. This fact probably indicates that the exothermic and endothermic reactions occur in equilibrium during thermal decomposition. For 6-hydroxyflavanone, the DSC curve shows a sharp exothermic peak between 468 and 


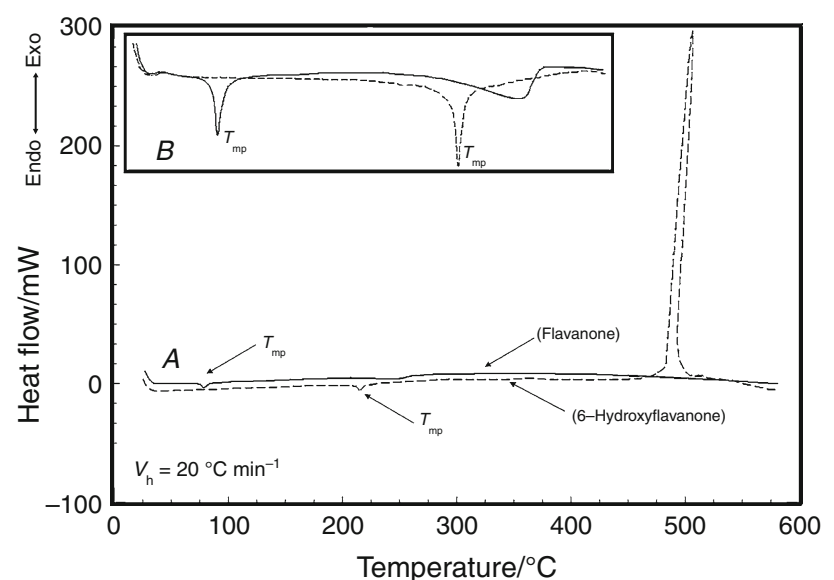

Fig. 4 DSC curves of flavanone and 6-hydroxyflavanone with mass sample of $2 \mathrm{mg}$ in an oxygen purge gas, heating rate of $20{ }^{\circ} \mathrm{C} \mathrm{min}{ }^{-1}$, in aluminum crucible

$505^{\circ} \mathrm{C}$, which was attributed to the combustion of the residual material.

Figures 5-8 show the TG/DTG curves of the flavonoids that were used to obtain the kinetic parameters. As can be seen from these curves, and also as expected, there is a displacement in the decomposition temperature with the increase in the heating rate. For analysis under both purge gases, the kinetic analysis was carried out for the main stage of thermal decomposition, namely in the temperature ranges indicated in Table 1, which were used in each heating rate to obtain the kinetic data.

\section{Kinetic parameters}

Figure 9 shows the plot of the heating rates $(\beta)$ in function of $1000 / R T_{\alpha}$ with the adjustment of the variation for activation energy $\left(E_{\mathrm{a}}\right)$. It can be observed from this figure that the corresponding activation energy $\left(E_{\mathrm{a}}\right)$ to heating rates of

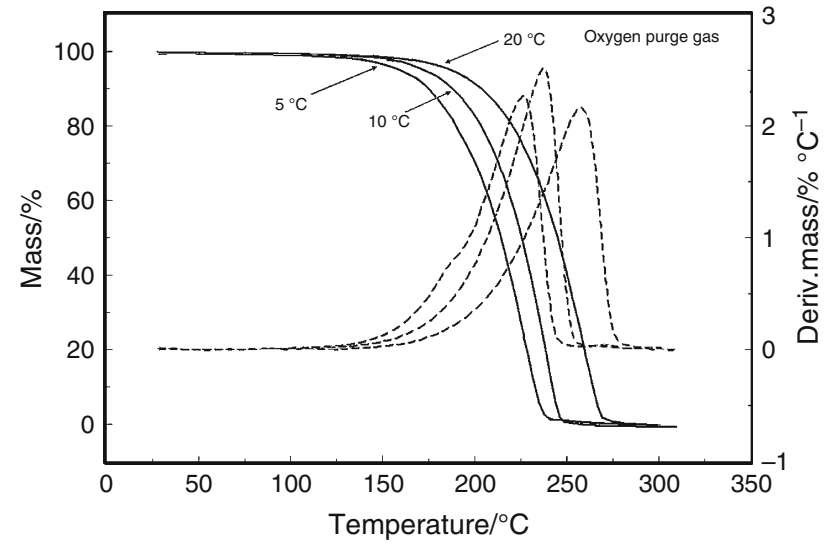

Fig. 5 TG/DTG curves of flavanone with mass sample of $2 \mathrm{mg}$ in an oxygen purge gas, heating rates of 5,10 and $20{ }^{\circ} \mathrm{C} \mathrm{min}{ }^{-1}$, in alumina crucible

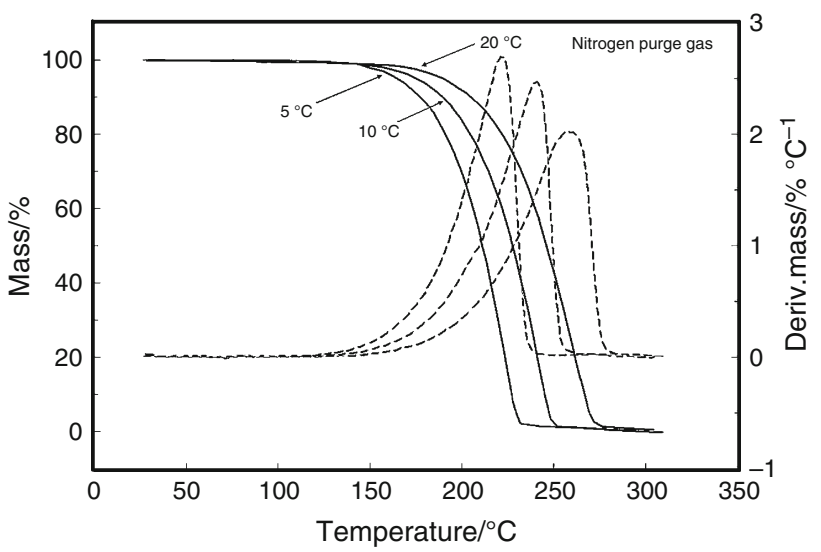

Fig. 6 TG/DTG curves of flavanone with mass sample of $2 \mathrm{mg}$ in a nitrogen purge gas, heating rates of 5,10 and $20{ }^{\circ} \mathrm{C} \mathrm{min}-1$, in alumina crucible

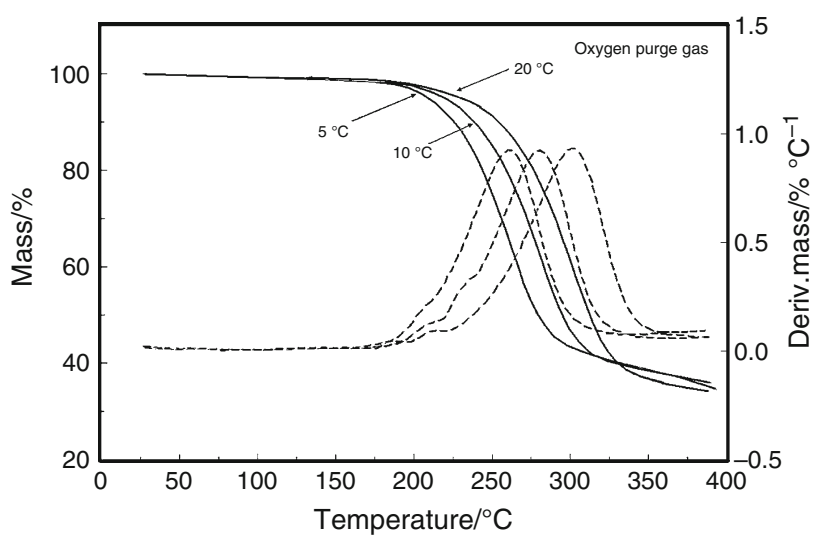

Fig. 7 TG/DTG curves of 6-hydroxyflavanone with mass sample of $2 \mathrm{mg}$ in an oxygen purge gas, heating rates of 5,10 and $20{ }^{\circ} \mathrm{C} \mathrm{min}{ }^{-1}$, in alumina crucible

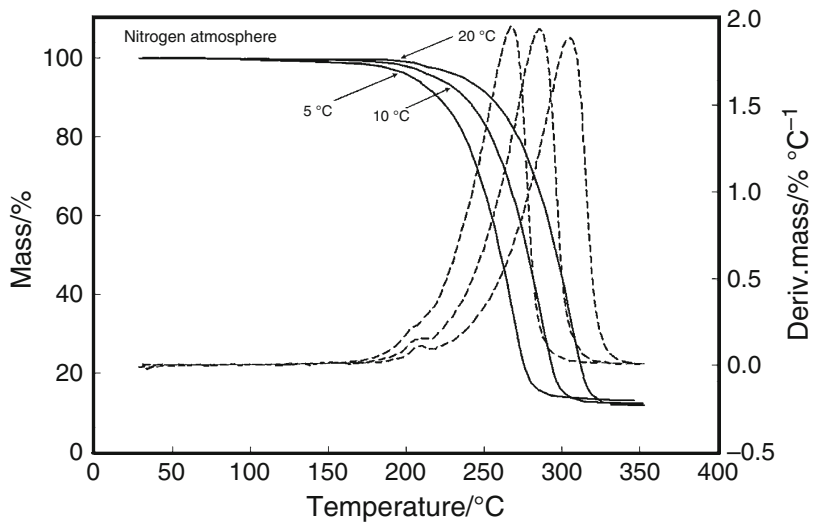

Fig. 8 TG/DTG curves of 6-hydroxyflavanone with mass sample of $2 \mathrm{mg}$ in a nitrogen purge gas and heating rates of 5, 10 and $20{ }^{\circ} \mathrm{C} \min ^{-1}$ 
Table $1 E_{\mathrm{a}} / \mathrm{kJ} \mathrm{mol}^{-1}$ and correlation coefficient $(r)$ for the thermal decomposition stages

\begin{tabular}{|c|c|c|c|c|}
\hline Compound & $\begin{array}{l}\text { Gas purge and stage } \\
\text { evaluated }\end{array}$ & $\begin{array}{l}\text { Temperature ranges } \\
\text { (DTG curves) }\end{array}$ & $E_{\mathrm{a}} / \mathrm{kJ} \mathrm{mol}^{-1 \mathrm{a}}$ & $r^{\mathrm{a}}$ \\
\hline \multirow[t]{6}{*}{ Flavanone } & (Nitrogen) & $\left(5^{\circ} \mathrm{C}\right) 130-240{ }^{\circ} \mathrm{C}$ & $71.69 \pm 0.02$ & 0.99974 \\
\hline & first decomposition stage & $\left(10^{\circ} \mathrm{C}\right) 139-262{ }^{\circ} \mathrm{C}$ & & \\
\hline & & $\left(20^{\circ} \mathrm{C}\right) 155-281{ }^{\circ} \mathrm{C}$ & & \\
\hline & (Oxygen) & $\left(5^{\circ} \mathrm{C}\right) 130-249^{\circ} \mathrm{C}$ & $77.16 \pm 0.01$ & 0.98925 \\
\hline & first decomposition stage & $\left(10^{\circ} \mathrm{C}\right) 141-258^{\circ} \mathrm{C}$ & & \\
\hline & & $\left(20^{\circ} \mathrm{C}\right) 160-279^{\circ} \mathrm{C}$ & & \\
\hline \multirow[t]{6}{*}{ 6-Hydroxyflavanone } & (Nitrogen) & $\left(5^{\circ} \mathrm{C}\right) 174-303{ }^{\circ} \mathrm{C}$ & $89.53 \pm 0.02$ & 0.99969 \\
\hline & 1st decomposition stage & $\left(10^{\circ} \mathrm{C}\right) 187-320^{\circ} \mathrm{C}$ & & \\
\hline & & $\left(20^{\circ} \mathrm{C}\right) 192-337^{\circ} \mathrm{C}$ & & \\
\hline & (Oxygen) & $\left(5^{\circ} \mathrm{C}\right) 178-322{ }^{\circ} \mathrm{C}$ & $74.71 \pm 0.12$ & 0.99723 \\
\hline & first decomposition stage & $\left(10^{\circ} \mathrm{C}\right) 190-345^{\circ} \mathrm{C}$ & & \\
\hline & & $\left(20^{\circ} \mathrm{C}\right) 212-356^{\circ} \mathrm{C}$ & & \\
\hline
\end{tabular}

a Average

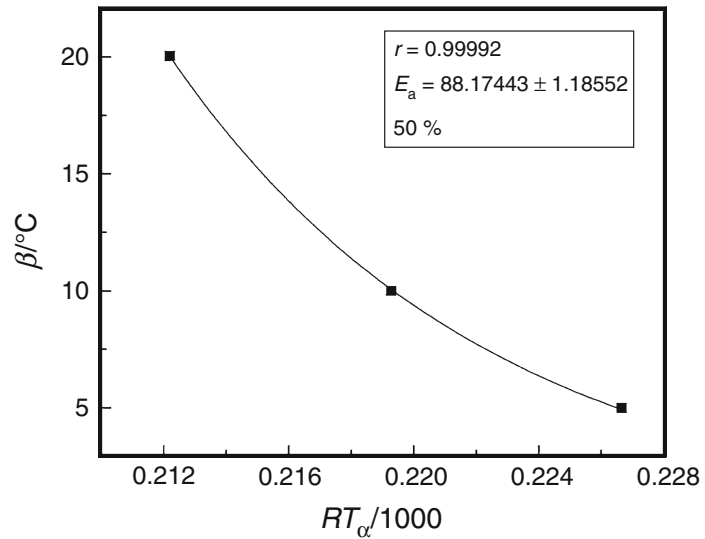

Fig. 9 Data of dispersion of $\beta$ versus degree conversion $(\alpha-50 \%)$ of the flavanone under a nitrogen purge gas for the decomposition stage

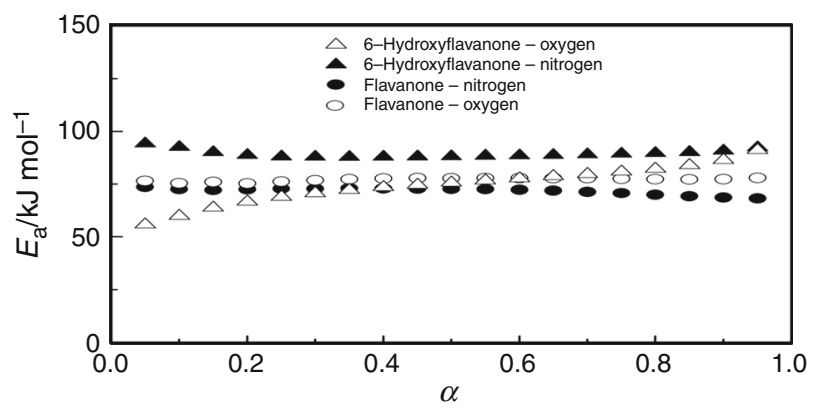

Fig. 10 Calculated $E_{\mathrm{a}} / \mathrm{kJ} \mathrm{mol}^{-1}$ as a function of $\alpha$ for flavanone and 6-hydroxyflavanone for the decomposition stage

5, 10 and $20^{\circ} \mathrm{C}$ was obtained in DTG curves (5-95\%). In addition, the kinetic parameters can be conventionally expressed with the extent of triplet TG curves, because three or more curves contribute to the measured data and also to reproduce the kinetic data [12-16, 18-21]. The values of the correlation coefficient $(r)$ and activation energy $\left(E_{\mathrm{a}}\right)$ are listed in Table 1 . The relations between the activation energy $\left(E_{\mathrm{a}}\right)$ versus conversion degree $(\alpha)$ value are shown in Fig. 10.

The thermal decomposition of these samples can be understood as an interaction of oxygen and nitrogen purge gases. We can then see that for the 6-hydroxyflavanone under oxygen, there is a decrease in activation energy, whereas for analysis under nitrogen, there was little increase. This fact indicates that the reaction between the 6-hydroxyflavanone and the oxygen gas favors the decrease in activation energy, because the reaction among the sample and oxygen favors the decrease in activation energy. However, the nitrogen purge gas, as is an inert gas, the chemical reaction is improbable, resulting in a reaction between the own molecules of the sample. This fact can be evidenced by TG curves, which demonstrate that the thermal stability under a nitrogen purge gas is higher than under the oxygen purge gas.

With the results obtained for flavanone under oxygen and nitrogen purge gas, it is possible to observe that the activation energy has the same tendencies of the plots to maintain the same contour and be parallel to each other, which demonstrates that the kinetic reaction only has one behavior. Moreover, as the flavanone does not have the hydroxyl group in the aromatic ring, the reactivity with oxygen and nitrogen was minimized, and therefore, the suggestion of a high reactivity of the 6-hydroxyflavanone with oxygen purge gas may be true. In addition, the intermolecular interactions can be more high between molecules of 6-hydroxyflavanone and therefore also promotes greater stability of the particles, while for flavanone 
molecules, the interactions are weaker due to the lack of the hydroxyl group.

\section{Conclusions}

In conclusion, this work showed the comparisons of thermal behavior of two flavanones by TG analysis which can be seen by their thermal properties. The thermal decomposition of the flavanone under a nitrogen purge gas showed that this compound has a homogeneous degradation process which can provide a good evaluation of the kinetic behavior. However, for the 6-hydroxyflavanone, it appears likely that this compound contains contributions from more than a single rate process. However, these compounds need to be evaluated in detail to understand the degradation mechanism to provide new information on the products of thermal decomposition. The kinetic characteristics for much thermal decomposition are markedly influenced by the several variables and may involve several degradation processes and therefore the mechanisms of the thermal decomposition $[18,19]$. In this paper, the kinetic evaluation indicates that the hydroxyl group in the aromatic ring can affect the kinetic behavior. Thus, the uses of complementary observations with others types of molecules may be useful to indicate a course to a better understanding the kinetic behavior.

\section{References}

1. Harborne JB, Williams CA. Advances in flavonoid research since 1992. Phytochemistry. 2000;55:481-504.

2. Gronquist M, Bezzerides A, Attygalle A, Meinwald J, Eisner M, Eisner T. Attractive and defensive function of the ultraviolet pigments of a flower (Hypericum calycinum). Proc Natl Acad Sci. 2001;98:13745-50.

3. Rousseff RL, Martin SF, Yutsey CO. Quantitative survey of narirutin, naringin, hesperidin, and neohesperidin in citrus. J Agric Food Chem. 1987;35:1027-30.

4. Heo HJ, Kim DO, Shin SC, Kim MJ, Kim BG, Shin DH. Effect of antioxidant flavanone, naringenin, from Citrus junoson neuroprotection. J Agric Food Chem. 2004;52:1520-5.

5. Jjamen D, Mbafor JT, Fomum ZT, Kamanyi A, Mbanya JC, Recio MC, Giner RM, Máñez S, Rios JL. Anti-inflammatory activities of two flavanones, sigmoidin A and sigmoids B, from Erythrina sigmoidea. Planta Med. 2004;70:104-7.

6. Smejkal K, Svacinova J, Slapetova T, Schneiderova K, DallAcqua S, Innocenti G, Závalova V, Kollar P, Chudik S, Marek R, Julinek O, Urbanova M, Kartal M, Csollei M, Dolezal K. Cytotoxic activities of several geranyl-substituted flavanones. J Nat Prod. 2010;73:568-72.
7. Toumi ML, Merzoug S, Boutefnouchet A, Tahraoui A, Ouali K, Guellati MA. Hesperidin, a natural citrus flavanone, alleviates hyperglycaemic state and attenuates embryopathies in pregnant diabetic mice. J Med Plants Res. 2009;3:862-9.

8. Bandgar BP, Gawande SS, Bodade RG, Gawande NM, Khobragade CN. Synthesis and biological evaluation of a novel series of pyrazole chalcones as anti-inflammatory, antioxidante and antimicrobial agentes. Bioorg Med Chem. 2009;17:8168-73.

9. Cao G, Sofic E, Prior RL. Antioxidant and prooxidant behavior of flavonoids: structure-activity relationship. Free Radic Biol Med. 1997;22:749-60.

10. Calderone V, Chericone S, Martinelli C, Testai L, Nardi A, Morelli I, Breschi MC, Matinotti E. Vasorelaxing effects of flavonoids: investigation on the possible involvement of potassium channels. Naunyn-Schmiedeberg's Arch Pharmacol. 2004;370:290-8.

11. Szliska E, Kostrzewa-Suslow E, Bronikowska J, Jaworska D, Janeczko T, Czuba ZP, Krol W. Synthetic flavanones augment the anticancer effect of tumor necrosis factor-related apoptosisinducing ligand (TRAIL). Molecules. 2012;17(10):11693-711.

12. Kobenik M, Bernabé GA, Ribeiro CA, Capela JMV, Fertonani FL. Decomposition kinetics of iron (III)-diclofenac compound. J Therm Anal Calorim. 2009;97:493-6.

13. Souza JL, Kobelnik M, Ribeiro CA, Capela JMV. Kinetics study of crystallization of PHB in presence of hydrociacids. J Therm Anal Calorim. 2009;97:525-852.

14. Kobelnik M, Fontanari GG, Marques MR, Ribeiro CA, Crespi MS. Thermal behavior and chromatographic characterization of oil extracted from the nut of the Butia (Butia capitata). J Therm Anal Calorim. 2016;123:2517-22.

15. Marques MR, Fontanari GG, Kobelnik M, Freitas RAMS, Arêas JAG. Effect of cooking on the thermal behavior of the cowpea bean oil (Vigna unguiculata L. Walp). J Therm Anal Calorim. 2015;120:289-96.

16. Capela JMV, Capela MV, Ribeiro CA. Nonisothermal kinetic parameters estimated using nonlinear regression. J Math Chem. 2009;45:769.

17. Zeraik ML, Ximenes VF, Regasini LO, Dutra LA, Silva DHS, Fonseca LM, Coelho D, Machado SAS, Bolzani VS. 4'Aminochalcones as novel inhibitors of the chlorinating activity of myeloperoxidase. Curr Med Chem. 2012;19:5405-13.

18. Vyazovkin S, Chrissafis K, Di Lorenzo ML, Koga N, Pijolat M, Roduitf B, Sbirrazzuoli N, Suñol JJ. ICTAC Kinetics Committee recommendations for collecting experimental thermal analysis data for kinetic computations. Therm Acta. 2014;590:1-23.

19. Ledeti I, Vlase G, Vlase T, Fulias A. Kinetic analysis of solidstate degradation of pure pravastatin versus pharmaceutical formulation. J Therm Anal Calorim. 2015;121:1103-10.

20. Zhang S, Wang S, Huang Z, Li Y, Tan Z. A kinetic analysis of thermal decomposition of polyaniline and its composites with rare earth oxides. J Therm Anal Calorim. 2015;119:1853-60.

21. Du R, Wu K, Zhang L, She Y, Xu D, Chao C, Qin X, Zhang B. Thermal behavior and kinetic study on the pyrolysis of Shenfu coal by sectioning method. J Therm Anal Calorim. doi:10.1007/ s10973-016-5475-x. 